Co-designing a dementia-specific education and training program for home care workers: The 'Promoting Independence Through quality dementia Care at Home' Project

Anita MY Goh ${ }^{123^{*}}$,

Colleen Doyle ${ }^{1}$,

Ellen Gaffy ${ }^{14}$,

Frances Batchelor ${ }^{1}$

Meg Polacsek ${ }^{15}$,

Steven Savvas ${ }^{1}$

Susan Malta ${ }^{12}$.

David Ames ${ }^{12}$,

Margaret Winbolt ${ }^{4}$,

Anita Panayiotou ${ }^{1}$,

Samantha M $\mathrm{Loi}^{3}$,

Claudia Cooper ${ }^{6}$,

Gill Livingston ${ }^{6}$,

Lee-Fay Low ${ }^{7}$,

Anne Fairhall ${ }^{8}$,

Jason Burton 9 ,

Briony Dow ${ }^{12}$ 
${ }^{1}$ formerly or currently from the National Ageing Research Institute, Parkville, VIC, Australia; ${ }^{2}$ The University of Melbourne, Parkville, VIC, Australia; ${ }^{3}$ Melbourne Neuropsychiatry Centre, Parkville, VIC, Australia; ${ }^{4}$ LaTrobe University, Bundoora, VIC, Australia; ${ }^{5}$ Benetas, Melbourne, VIC, Australia $;{ }^{6}$ Division of Psychiatry, University College London, London; ${ }^{7}$ University of Sydney, Sydney, NSW, Australia; ${ }^{8}$ Consumer advocate; ${ }^{9}$ dementia360.

*Corresponding author

Email: a.goh@nari.edu.au

ORCID ID: $\underline{\text { https://orcid.org/0000-0003-0159-5926 }}$

Twitter: @dranitagoh

Acknowledgments: We acknowledge the assistance of project investigators Professor Constantine Lyketsos, Professor Philip Clarke and Associate Professor Samuel Scherer, the expertise of our training and education expert Erica Wise, and the invaluable contribution of the members of the PITCH Project Advisory Group.

Word count: 5136 without boxes and table 


\section{Co-designing a dementia-specific education and training program for home care workers: The 'Promoting Independence Through quality dementia Care at Home' Project}

Undertaking co-design with the end users of services has rapidly evolved as the best-practice approach to program design, development and implementation. Increased interest in using participatory co-design in dementia care has drawn attention to the need for evidence-informed methods for facilitating the meaningful involvement of people with dementia and their family carers in codesign activities. The aim of this paper is to describe the co-design framework used in the co-design of a dementia specialist training program for home care workers. The Promoting Independence Through quality dementia Care at Home (PITCH) program is a successful example of co-design methodology used across multiple project stages and with various stakeholder groups, including people living with dementia, family carers, home care workers, managers and researchers. Co-design methods were tailored to each stage, purpose, and stakeholder group, and to facilitate the involvement of people living with dementia. Findings provide unique insights into optimising input from co-design partners, including people living with dementia; the methodology, conditions and requirements for participants to co-design and implement ideas; and perspectives on the enablers and challenges of using co-design in this population. In this paper, we present a comprehensive approach for involving people living with dementia as active and equal contributors in inclusive and meaningful participatory co-design.

Keywords: dementia; family carer; co-design; training; design process 


\section{Introduction}

Co-design is a method of facilitating the meaningful involvement of consumers and people with lived experience in research and practice (Blomkamp, 2018; Leorin et al., 2019) and is increasingly being incorporated into research designs when developing interventions to ensure user needs are adequately addressed (Steen et al., 2011; Trischler, Pervan et al., 2018). People living with dementia, particularly those with later stage dementia, have historically been largely excluded from participatory research (O’Sullivan et al., 2013), however, the use of co-design methods can facilitate the active, meaningful involvement of people living with dementia in such research, including in service design and delivery (Swarbrick et al., 2019). The dementia advocacy movement in particular has supported this shift, promoting active rather than passive involvement of people living with dementia in research (Bryden, 2015).

Co-design as a participatory design approach validates lived experience, placing it on equal footing with professional experience. In co-design, people who use, or are affected by, a service have a key role in providing expertise based on their lived experience, and are invited to participate in its design, implementation, review and/or delivery. As a result, innovations to service design or improvement are more likely to be useful, effective and sustainable (Trischler, Kristensson \& Scott, 2018). A recent codesign project of an intervention with family carers of people living with dementia reported 'experts by experience' particularly enriched the process of designing an intervention by ensuring it was clear and engaging and by their knowledge of overcoming barriers to implementation (Rapaport et al., 2018).

While frameworks for co-design exist for use in general health settings (Trischler et al., 2019; Bird et al., 2021) and also for specific use with groups with health conditions (Grant et al., 2021; Jessen et al., 2018) there is little evidence for which particular frameworks and methodology are most effective for engaging people 
living with dementia and their family carers in the co-design process. This is despite studies suggesting the effectiveness of co-design is dependent on its process, including which users are involved and how their involvement is facilitated (Trischler, Pervan et al., 2018). A systematic review investigating the methods used to engage people with dementia (and their carers) in co-design, and the barriers and facilitators to co-design in this population is being conducted by the authors to add to the evidence-base (PROSPERO 2018 CRD42018088748).

\section{Definition of co-design}

Variation in the conceptualisation and operationalisation of co-design exists within the literature, particularly when involving people living with dementia (Wang et al., 2019), and when discussed in relation to overarching design processes of co-creation and co-production (Niedderer et al., 2020; Tsekleves et al., 2020). In this study, we follow the principles of Sanders and Stappers' (2008) approach to co-design: shared decision making; equal partnerships and emphasis on creativity and innovation; engaging end-users in an equal partnership in the idea generation; and development of products, resources and services intending to address their needs

Most earlier co-design studies involving people living with dementia in developing interventions are predominately outcome focused (i.e. designing products orprograms) and typically report the results of these of co-designed outputs (Faucounau et al., 2009; Robinson et al., 2009), rather than providing guidance on methodology, such as how co-design activities should be conducted or facilitated with people living with dementia. Studies have described key considerations for supporting ongoing involvement of people living with dementia in in co-design processes (Goeman et al., 2019; Treadaway et al., 2019), and traditional co-design tools, engagement techniques and processes may require modification in order to use with people living with 
cognitive and sensory impairments (Hendriks et al., 2015). The use of personalised approaches (Branco et al., 2017), art based methods (Tsekleves et al., 2020) and probes such as visual cards and diaries (Niedderer et al., 2020) have been explored as ways to engage people living with dementia in co-design processes. More work evaluating outcomes of involving consumers (including people living with dementia) in co-design would also be useful and is currently lacking.

One approach used in co-design is the World Café approach, which has been used successfully in many health-related studies. The World Café methodology promotes the involvement of consumers and communities in research through meaningful partnerships (Brown,2005) and is an effective and flexible format for hosting and fostering constructive large group dialogue. This approach privileges the involvement of consumers and communities in research by creating meaningful partnerships through an interactive exchange of insights on issues, utilising a 'conversational process' among groups, and thereby accessing collective intelligence (Fouché \& Light 2011). In a World Café, all participants are regarded as experts of their own lived experience and are supported to contribute experiential knowledge. There is no pressure to reach consensus, as diverse perspectives are encouraged and valued. The World Café methodology has been found to be a valuable, participatory, flexible method that can be used for meaningful research collaboration and prioritisation with marginalised communities, and aligns with high-quality engagement for research (MacFarlane et al., 2017). Despite its potential, there is limited evidence in the literature of the use of World Cafés with people living with dementia and family carers. Swanson (2014) employed the method with people living with dementia and family carers to improve dementia services, and Smith \& Phillipson (2020) with family members of 
people living with dementia to improve care and support people with dementia in residential aged care facilities.

The aim of this paper is to describe the methodology used in the co-design of a dementia training package for home care workers, and the approach for supporting the involvement of people living with dementia, family carers and care workers. It reports feedback from participants about the co-design experience and discusses the strengths and challenges of the approach taken.

\section{Methods}

\section{Co-design method for the PITCH program}

The objective was to co-design an education program to upskill home care workers by improving their dementia literacy and confidence, improve quality of care for people with dementia and reduce family carer burden (the program is currently being formally tested through a randomised controlled trial, ACTRN12619000251123). The key principles of co-design used in this project include the participation of all stakeholder groups in the development process, the creation of ownership (collective leadership) and using outcomes to assess effect (Bradwell \& Marr, 2008). The research team created a culture to uphold the principles of co-design and relationship building and all activities were centred on a group of people working together as equals. The five stages in our methodology and how they relate to co-design processes (e.g. Barbera et al., 2017 and Sanders \& Stappers, 2008) are outlined in Table 1.

Table 1. The stages of the PITCH co-design methodology and how they relate to codesign theory processes. 


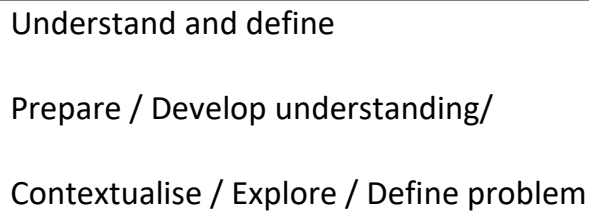

Stage 4. Piloting of program
The Project Advisory Group was involved at every stage

Ethics: This project received ethics approval from the Austin Hospital (HREC17Austin537). Signed informed consent was obtained for all stages of the project from all participants or from their nominated proxy, before any co-design activities took place (i.e. prior to interviews, focus groups, and workshops). The exception was Project Advisory Group members, who were not required to provide informed consent.

Stage 1. Establish key partnerships and Project Advisory Group (PAG)

Based in Australia, the PITCH project involved a large international team of researchers, people living with dementia, family carers, and home care workers, case managers and service managers from home care service providers. Other collaborators included international dementia training and education experts, and representatives from industry, advocacy bodies and healthcare providers.

The research team established a project advisory group (PAG) of 17 members, including representatives from aged care assessment teams, family carers, advocacy 
bodies, government departments, service providers, people living with dementia (including young onset dementia), and home care workers. This group met quarterly, chaired by a dementia advocate and family carer of someone living with dementia. Members attended in-person or via video conference. Terms of Reference were developed collaboratively with the members, and the PAG provided direction and guidance to the project team, communicated the status of the study to relevant key stakeholders, and provided guidance and input into the conduct of all project stages. The PAG members were also involved in the co-design and development of the PITCH project and program, and ensured the project was respectful of the experience of the people living with dementia and their carers.

All consumer representatives were paid \$AUD60 per hour for their time at each meeting (whether attendance was in person or virtual) via gift cards, and taxi vouchers were provided for in-person meetings. The chair was paid a yearly honorarium. For the duration of the project, each member living with dementia was partnered with a researcher, and this relationship was kept as consistent as possible, with the researcher providing documents and contacting the person before meetings for any clarifications and questions, and to organise the logistics of attending the meeting. They also sat next to each other during in-person meetings, so the researcher could optimise their participation and privilege their voices (should they need it), by directing them to the correct documents, checking their comfort and understanding (including the speed and method of information presentation was appropriate, and if they wished to receive modified written materials with larger text size on one-sided copies), and by ensuring they did not feel rushed when engaging with the group. This approach ensured that they could continue to participate as their symptoms of dementia progressed over the fouryear project. 
The co-design process included a qualitative study exploring perceptions of home care delivered by service providers in Victoria, Australia, in 2018, and how it could be improved. Participants were recruited using purposive sampling from eight service provider partners, who disseminated advertisements and letters of invitation to their staff and clients living with dementia. Those interested in participating were asked to contact the researchers directly for study information provided by telephone or mail. Forty-three participants were interviewed or took part in focus groups. Four people living with dementia, 15 family carers, 10 home care workers, and 14 managers (nine case managers and five service managers) participated. All four people with dementia had received a diagnosis of later onset Alzheimer's disease, and were at least seven years post diagnosis. Participants were interviewed using a semi-structured interview schedule, designed to better understand the experiences of people living with dementia, their carers, and home care professionals regarding home care. Individuals living with dementia were able to participate on their own or with their family carer, and family carers could choose to participate without the person they were caring for, depending on their preference, and at the location and time of their choice. Of the four participants with dementia, three were interviewed on their own, and one was interviewed together with their carer. The participants living with dementia mostly nominated to be interviewed in the morning and in their own homes, to maximise comfort and cognitive ability. Interviewers were experienced in dementia research and in communicating with people with cognitive impairment (such as using the strategies to promote effective communication with a person with dementia in Jootun and McGhee (2011). The initial qualitative themes were reviewed by the PAG, and results have been published (Polacsek et al., 2019). 
Forty-six people with dementia, their family carers, and home care staff participated in four community-based co-design workshops using the World Café methodology, where participants came together (in person) in a group format to codesign the content, length, delivery and setting of the PITCH training program (Fouché \& Light, 2011). Participants were recruited from those who took part in the qualitative study in Stage 2, and via advertisements and service provider and research institute newsletters. Recruitment of family carers and people living with dementia was facilitated via patient and carer advocacy organisations. Five individuals with dementia participated as co-designers, attending multiple workshops. Four of these individuals attended with their family carer ( $\mathrm{n}=13$ carers who also attended multiple workshops).

The workshops were conducted in accordance with World Café's seven integrated principles: (a) set context; (b) create a hospitable space; (c) explore the questions; (d) encourage everyone's contribution; (e) connect diverse perspectives; (f) listen together for patterns; and (g) share collective discoveries (Box 1).

Box 1. World-Café forum methodology.

1. Participants were welcomed to the café and invited to sit in groups of approximately 4-5 participants at separate tables. The facilitator set the context for the event, and introduced the principles of a World Café and ground rules for participation.

2. Each table had a table host, and participants brainstormed and discussed the table topic. The tables were covered with white paper 'tablecloths' and participants were provided with pens and markers to take notes, write, and/or illustrate the ideas from the discussions. At the end of the 'table' discussion (which typically lasted about 15 minutes), participants rotated as a group to another table to discuss a different question. 
3. The 'tablecloths' with the notes and ideas from each table were put placed on the walls after each table rotation for further sharing, and participants provided with sticky, coloured paper dots. Participants were instructed to stick them on the 'tablecloths', to indicate their top three priorities or responses to questions. They were also given blank post-it notes and encouraged to use them to add to the 'tablecloths'. Researchers were available to scribe if necessary. This method maximised participation in large group discussions and provided participants with additional and multiple opportunities to have a voice in the generation of responses to questions as well as in the group priorities.

4. The table host recorded discussions and remained at the table to provide a brief summary to the incoming group about the discussions of the preceding group to encourage cross-fertilisation of ideas and knowledge. As succeeding groups responded to the question, a rich set of responses gradually developed.

5. After all groups had responded to each topic, responses from all discussions were shared with the full group. Key responses for each question were summarised and opportunity provided for participants to offer any further input and feedback. This also served as a form of member checking before the workshop concluded. Participants completed evaluation forms on the workshop process.

Data consisted of notes and observations, participants' tablecloth comments, summary sheets from the scribe, results of activities, photos, written notes, and drawings. Participants could also record key insights from the co-design process (in the form of short video recorded 'vox-pops').

At the preparation stage, the research team and PAG considered how to maximise the participation of all participants, particularly of the people living with dementia. The underpinning philosophy was that optimising the co-design methodology for people living with dementia also optimised participation for all. The methodology was designed to ensure participants would feel safe and have their voices heard, with activities suitable for participants' cognitive abilities. The cafes were three hours, with frequent structured breaks. Throughout, the research team encouraged participation, actively managed group dynamics, and were mindful of transparent and rapid conflict resolution and negotiation. The following principles were followed: 
- Ensure the voices of people with dementia were heard (facilitators specifically asked, and provided ample time, for people with dementia to ask and respond to questions);

- Opportunities were given for the persons living with dementia to have a support person (one-on-one support was offered to the people living with dementia, either by their family carer or by a member of research staff);

- Ensure peer support for people living with dementia and their carers (there was a small cohort of people living with dementia and a larger group of family carers);

- Provision of adequate breaks in the program, and the availability of quiet rooms participants could use at any time for a break;

- People living with dementia and their carers were grouped together for table discussions, separate from home care workers and their managers;

- Tasks involved a combination of limited choices as well as 'blue sky' thinking;

- Instructions were repeated and re-iterated, and a range of formats verbal and written) were provided;

- Language used was respectful and inclusive, and adhered to the language guidelines from Dementia Australia (2018);

- Handouts and slides were developed using a colour scheme with high contrast levels, plain backgrounds, and large, clear sans serif font, to improve readability and assist those with memory or visual impairment.

Table hosts were health-care professionals, research staff, service provider staff and family carers. Unfortunately, none of our co-designers living with dementia accepted invitations to host a table. Table hosts were briefed about the above considerations, the World Café principles and approach, and provided with written instructions prior to the cafés. All hosts were experienced in interacting with people 
with cognitive impairment and were mindful of creating space for those with dementia to participate and provide input.

\section{World Café workshops 1 and 2: Topic areas and co-design activities}

Workshops 1 and 2 focused on further understanding the problem and idea generation of what the PITCH program should contain. The topic areas were informed by the qualitative study and refined by the research team and PAG to stimulate discussion and to explore participants' needs and concerns about dementia care delivered by home care workers, dementia literacy and knowledge, attitudes, practices, and any other determinants that influenced preferences for the PITCH program.

To develop a deeper understanding of the problem in the initial stages of codesign, we used creative tasks such as developing 'ideal' home care worker personas, narratives and storytelling. Creativity plays an important role for people living with dementia (Camic et al., 2018), as it is an engaging social activity that can provide a conversation model for people with dementia, even in more advanced stages (Fels \& Astell, 2011) and has been shown to improve communication and affect in people with dementia, relationship quality (Vigliotti et al., 2018), communication and mood (Phillips et al., 2010), and alertness (Fritsch et al., 2009). As mentioned above, people living with dementia and their carers were grouped together for discussion, but separate from home care workers and their managers. Additionally, managers were also separated from the home care workers, to minimise boundary issues or power inequities. The table topics and activities are listed in Box 2.

Box 2. World-Café table topics and activities for workshops 1 and 2

Table 1. All participants created their 'ideal' home care worker. They were provided with nine preprinted values cards and 3 blank cards where they could write their own values. The group was 
instructed to pick their top five attributes of a home care worker and stick them to a generic figure of a person, and to draw and decorate this 'ideal' home care worker. The values were Knowledge of dementia, Kindness, Empathy, Flexibility, Compassion, Dependability, Respect, Courtesy, Communication Skills. These were adapted from the results of the qualitative interviews and the Personal Values Card Sort (Miller et al. 2001).

After the first table, the people with dementia and family carers were asked the following questions:

\section{Table 2.}

Thinking about the person you just created, what do you think home care workers need (to know) to do their job well?

What does this home care worker need to know about you?

\section{Table 3.}

What knowledge/skills should home care workers be taught in a new training program?

What things do you think home care workers need to know about the best way to support you and understand you or to respect your needs?

The home care workers and managers were asked the following questions:

\section{Table 2.}

What do you think would be good to learn in dementia training?

What information / skills do you think home care workers need to learn to be able to better support the person living at home with dementia and their family carers?

\section{Table 3.}

What format should the new training program take?

What is the preferred setting for delivery of the PITCH program, such as in-person, online, or a mix? Who should provide the training?

What duration and how often should sessions be?

What would make the information in the program more meaningful and useful to you?

What cost is acceptable for this sort of program? 
All groups also moved to Table 4 to discuss stories and scenarios, where the questions were:

Tell a story about giving or receiving home care

Describe a situation where something was challenging

One story per table was shared with the wider participant group (shared by either the Table Host or the participant, if they were comfortable doing so). Table hosts wrote down all stories discussed at the table.

At the end of the workshop, the data were transcribed and imported into QSR International's NVivo Version 11 software for Windows (2015) for thematic analysis (Braun \& Clarke, 2013) independently by two research team members who were present at each workshop. The two researchers discussed their initial coding and themes in order to reach consensus on themes and hierarchy of coding structure. Emerging key themes were displayed as an explanatory model (Miles et al., 2019). A third researcher who also attended the workshops reviewed the emerging themes. Any difference of opinion was discussed among the researchers and PAG until agreement was reached.

\section{World Café workshops 3 and 4: Topic areas and co-design activities}

Thirty-four participants who attended the first workshops were invited to this second round of workshops two weeks afterwards, which focused on ideation and further refining ideas to co-design a prototype PITCH program with specific modules and learning objectives. The World Café methodology was used again, which served to enhance participant checking, as they were able to see and verify how their contributions in workshops 1 and 2 had been used to co-design the program.

A prioritisation activity was used in workshops 3 and 4, where the top key priorities and suggestions identified from the previous workshops 1 and 2 were collated 
and presented. There were between 9 and 14 priorities from the workshops, and participants were instructed to select 5 topics of most interest/importance from the list. They could also list other topics of interest/importance. Brainstorming activities were also conducted. In this way, participants provided refinement, feedback, adaptation, and fine-tuning of the content and delivery of the prototype PITCH program. Table topics and activities are listed in Box 3.

Box 3. World Café table topics and activities for both workshops 3 and 4

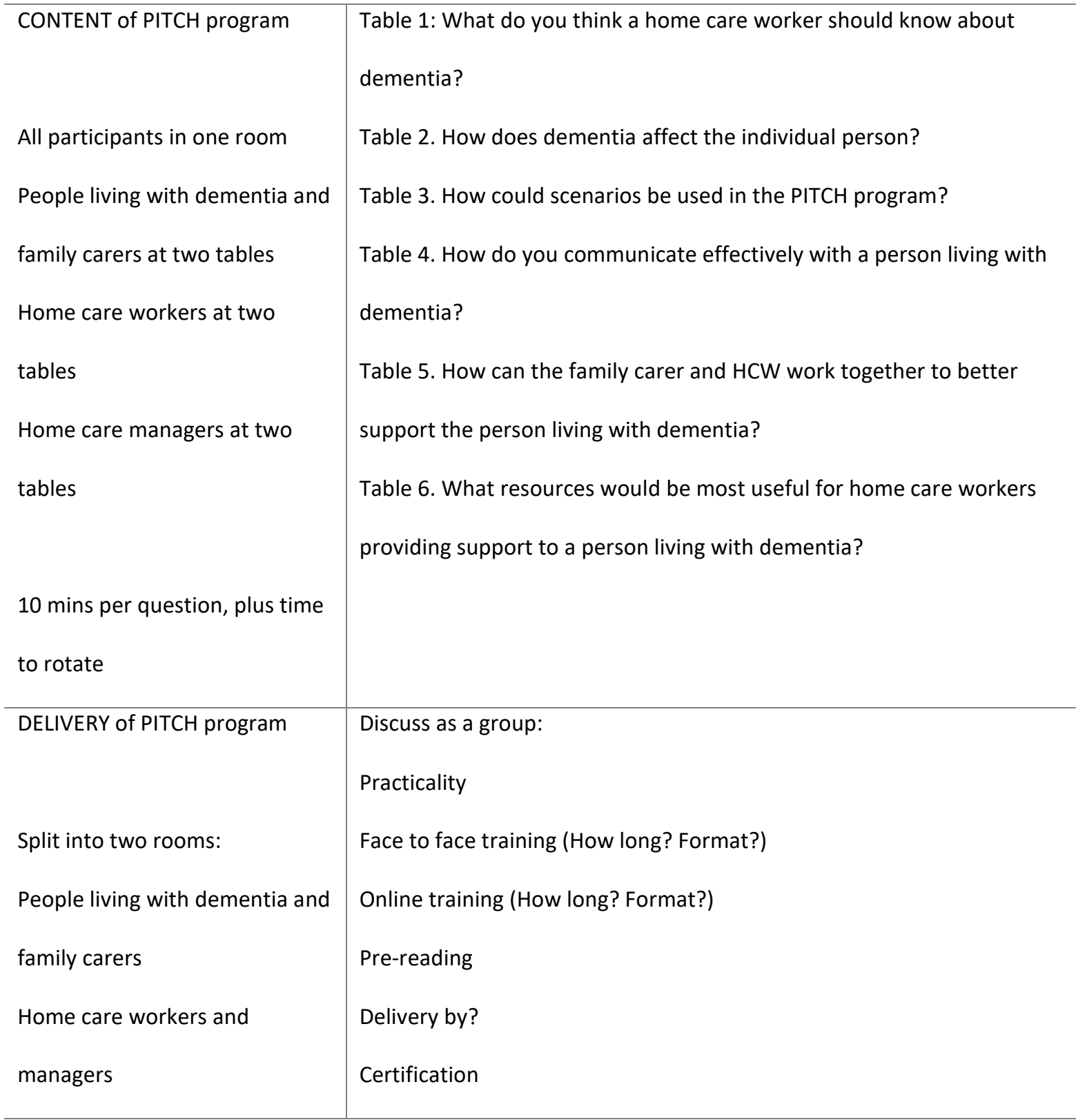




\section{Methods of evaluation}

At the end of the co-design workshops (Stage 3), participants completed (anonymous) evaluation forms regarding the co-design methods and approaches used. Thirty-seven co-design participants completed evaluation surveys for Workshops 1 and 2, and 27 participants completed evaluation surveys for Workshops 3 and 4. Participants also completed an evaluation form at the end of each pilot (Stage 4), , containing questions around presentation content, delivery, organisation and satisfaction with the training, and included questions regarding application and confidence. These results, together with the project team's observations and experiences, wereused by an education expert and PAG to further develop the training materials.

\section{Findings}

\section{Participant feedback on the co-design methodology}

The evaluation surveys indicated people involved in the World Cafés were highly satisfied with the process and felt able to contribute as co-designers. The positive feedback from all participants supports the co-design approach used in this project (see Box 4 for examples of feedback, and Figures 1 and 2 for a summary of participants' evaluations).

Box 4. Examples of (anonymous) feedback received by participants, in response to the following free text questions on the evaluation form: 1) What are the key things you have learned? 2) Do you feel the process could be improved in any way? If so, please explain how; 3) Other comments that may help improve our process? Any other comments in general? 
I wanted to share how wonderful the workshop was, and really felt it captured the gaps in current training and areas we can really make a difference.

It was great to be part of the workshops and have the opportunity to not only express my opinion, but also to hear and learn from the views of others.

We felt very welcome and our thoughts respected.

I feel the two workshops have been very well thought out and prepared. There was a relaxed feel and an inclusive feel with us all.

I loved the way it was organised with the World Café.

** Figures 1 and 2 to be placed around here**

The free-text responses highlighted some areas for further improvement. Participants in workshops 1 and 2 suggested more workshops for ongoing review and evaluation, more groups with participants separated depending on experience levels (e.g. care workers with 1-5 years' experience compared with those with 5-10 years; also case managers with 1-5 years' or 5-10 years' experience), and more time to exchange ideas/issues with providers and care workers. Some participants suggested the workshops should include a mix of both paid and unpaid family carers, but others suggested these groups have independent co-design workshops, where service providers and paid carers were not present in the same workshop. Several participants also noted an outline of content and processes of the workshops should be sent before the sessions (perhaps via email), to help participants process information prior to the workshops, which would help them focus on the most important issues.

For workshops 3 and 4, areas for improvement included more time allocated within the day and longer sessions to allow for greater discussion, additional workshops, and minimising overlap in questions. Participants also commented that providing the results of workshop 1 and 2 prior to the workshops (via email) would 
have allowed a considered response and for each group to understand the differing priorities between care providers and care recipients. Other suggestions were to keep the groups diverse instead of separate to enhance interaction with all groups, and combining all sectors together to discuss their perspectives and find common ground.

\section{Stage 4: Piloting of program}

The prototype of the PITCH program co-designed in Stages 1-3 (and associated materials such as slides, videos, and workbooks) was piloted in the following groups of end-users to test whether the co-designed product met their needs: 11 home care workers and their managers in an experienced dementia specialist home care service provider (Alzheimers WA); four home care workers and their managers in a nondementia specialist home care service provider (Mercy Care); six PAG and research team members.

The average responses received on anonymous participant evaluation forms rated the co-designed end product highly. For example, Figure 3 shows the results of the evaluation forms from the first pilot session with 11 experienced dementia specialist home care workers.

** Figure 3 to be placed around here**

\section{Stage 5. Final development of training materials}

The combined results of co-design stages 1-4 were then shared with national and international collaborators, education experts and design consultants, in order to refine the final PITCH training program. In this stage, the co-designed content and materials were not significantly altered, and the amendments made predominantly related to shortening content, improving the aesthetics of the materials, and developing the content into learning packages that complied with adult learning principles. 


\section{Discussion}

The significance of this paper lies in its description of the process of conducting co-design with a range of stakeholders, including people living with dementia and their family carers, as well as home care workers and managers. The process optimised input from service providers, service managers, case managers, home care workers, people with dementia, and family carers, and was designed for each group to provide meaningful contributions as true project partners, so the ultimate PITCH program genuinely met the needs of end-users. The program is currently being tested through a randomised controlled trial.

Apart from designing the co-design processes with the person living with dementia in mind, as described in the methodology, other aspects of the methodology that facilitated meaningful partnerships and effective co-design (drawn from the observations of the research team and discussions with the PAG) were:

\section{Team commitment to co-design}

Having a team of researchers and advisors who were interested in each other's views and the views of the broader participant group was essential in ensuring the end product achieved the desired outcomes.

\section{Peer support for people with lived experience}

Peer support was key to the involvement of people with lived experience in this project and is known to be critical in engaging people with a disability in research or advocacy (Repper \& Carter, 2011). However, it is less clearly articulated in research involving people with dementia and their carers. A recent review of patient and public involvement (PPI) in dementia research in the European Union found a need to understand the process and the costs of PPI as well as better evaluations, but there was 
no mention of the support needs of PPI participants (Miah et al., 2019). The Briefing Notes for Researchers for public involvement in NHS, public health and social care research (INVOLVE, 2012) suggest it is important to have more than one person with lived experience represented in a research project, but their rationale is to generate diversity of experience, rather than to provide peer support.

\section{Experienced family carer chair of PAG}

The Chair of the PAG is an experienced family carer and chairperson, who ensured the voices of people living with dementia and those in rural areas (who attended via a video platform) were heard. Strategies introduced by the chairperson included asking presenters to pause at regular intervals to give time for reflection and comment, and taking time to question group members and invite their input. The chairperson worked with the research team to set the agenda and to reduce the number of agenda items to facilitate inclusive and robust discussion between all participants.

\section{Café style workshops}

The World Café methodology is designed to produce a welcoming atmosphere as well as activities enabling equal contributions from all participants. The café-style atmosphere was enhanced by environmental design considerations, including a convenient central location, ensuring comfort with optimal temperature and seating arrangements, plentiful catering and room decorations (such as flowers and posters). We were able to hold all our workshops face-to-face, but in the light of the COVID-19 pandemic and the restrictions on face-to-face meetings, future approaches will need to consider on-line co-design workshops. 
The co-design methodology used in this project was effective for our project, and we plan to use this methodology in future studies. However, in reflecting on our experience, these are some challenges to address for any future work:

\section{Management of competing views and expectations}

Our methodology prioritised the benefits of hearing each other's points of view and the opportunity for all groups to work together on a common task. There was careful management of this in the workshops, where, in this instance, we decided to group people living with dementia and their carers together for table discussions, with the other tables comprising of those providing care. This approach was used as a response to some negativity and service complaints that were detected towards home care workers in the qualitative interviews held prior. We did not want to expose home care workers to this directly in the co-design workshops, and did not wish the workshops to be a forum for complaints (towards the home care workers or towards the people with dementia or their carers). Although we separated the groups for the table discussions, we ensured that there was adequate time in the agenda for group discussion (such as in the lunch period, and in the summary and discussion sessions) so all codesigners could directly hear and discuss (together) the views of other participant groups. Other co-design projects may consider combining all groups of co-designers, if appropriate.

As expected, the co-design process highlighted diverse views and expectations regarding the training program. For example, family carers preferred that home care workers attend a full year of weekly evening classes to attain a specialist certificate in dementia care for home care workers, while case managers mentioned the unfeasibility of this and suggested training could take place in the 15-minute handover between work shifts. After refining with the co-design participants in the second series of workshops 
(particularly the question of practicality), the research team worked with a learning designer to incorporate the content into a feasible program, which was two three-hour workshops, guided by the preferences of the stakeholders and considerations of feasibility. Whilst we did not go back to the workshop co-design participants after the final design, we discussed the final structure of the PITCH program with the 17 codesigners on our PAG, and conducted piloting with three groups of separate codesigners. Although it was challenging embedding multiple stakeholder groups as codesign partners, the diverse opinions and viewpoints resulted in an outcome more likely to meet the needs of all end-users. Participants heard different points of view to inform their opinions, such as practical and financial constraints, and the resources required to deliver programs such as PITCH. Overall, there was value in sharing competing opinions, as participants heard each other's points of view and rationale.

\section{Co-designing with people living with dementia and family carers}

Cognitive impairment can impact meaningful participation in a range of activities, including participatory co-design. As reflected in this paper, there were accommodations and modifications made to facilitate the involvement of people with dementia. These were not challenging to implement, and the benefits of involving the dementia community far overweighed any efforts made to accommodate them. Although dementia is a progressive illness, this did not significantly affect the co-design workshops in this project, which spanned approximately two months for each participant. However the co-designers living with dementia who were members of the PAG were involved in the project for approximately four years, and their symptoms did progress. 


\section{Translating ideas into a training program}

Another challenge was in translating the ideas developed and collected in the codesign process into two three-hour workshops that were based on adult learning principles. The use of adult learning principles meant that the program had to be goal oriented, time given for participants to share their prior experience, to be interactive, rather than didactic and to include real life practical examples. This all takes time, which was initially difficult to estimate. The first pilot test revealed our material was too extensive to cover in a six- hour training program. Thus, some ideas from the co-design process had to be excluded. This process also took much longer than expected and required assistance from the PAG, and additional expertise from a learning designer and education expert, which had not been anticipated. This expert consolidated the ideas into learning packages, attending all PAG meetings to liaise with members.

\section{Limitations and future research}

We did not conduct a formal evaluation of the co-design process. Future research is needed to evaluate co-design from the perspectives of all stakeholders, as well as the outcomes of co-design compared with researcher-led studies. More strategic purposive sampling would strengthen participant diversity, particularly to reflect the cultural and linguistic diversity of the aged care workforce in Australia.

One of the more persistent challenges of engaging people living with dementia and their family carers in research is recruitment of adequate numbers (Bartlett et al., 2019), which we experienced in this study. There may be barriers such as a lack of awareness about research participation opportunities, a lack of suitable study partners, and/or the perception that involvement in a research project can be too difficult. Potential family carer participants are living with or caring for someone with a disabling and progressive condition which has many challenging aspects, and may not have the capacity to 
become involved in a project. Further, people who are willing and able to become involved are often called upon regularly and may be involved in a range of projects, resulting in participation fatigue, and may also become less representative of the population as they become more familiar with research processes. Other challenges relate to the overall health of the person with dementia and their carers. Future research should seek to enhance the authenticity of the principles of co-design by targeted recruitment of people living with dementia to host tables in the co-design workshops, and to chair/co-chair the PAG. We hope that recruitment will be facilitated in the future by more awareness of co-design projects such as the one described here, and co-design teams using our findings to optimise the experience of co-design with the dementia community, leading to positive outcomes and experiences for all.

\section{Conclusion}

This paper provides insights into the methodology, conditions, and requirements that enable multiple stakeholders, including people living with dementia and their family carers, to come together to effectively co-design a shared outcome.. Strategies are presented for facilitating meaningful participation as partners in the co-design process, and reflect the lessons learned about the enablers and challenges of codesigning with this population. Our findings highlight the importance of peer support for people with lived experience of dementia, having people with lived experience in leadership roles, designing the process to facilitate active engagement of people living with dementia, having welcoming, warm and well-catered World Café workshops and a strong team commitment to the overall process. Together, these elements underpin effective co-design in dementia research. 
Funding and Disclosure Statement: This work was supported by the Australian National Health and Medical Research Council under Grant 1137705. No potential competing interest was reported by the authors.

\section{References}

Barbera, E., Garcia, I., \& Fuertes-Alpiste, M. (2017). A co-design process microanalysis: Stages and facilitators of an inquiry-based and technologyenhanced learning scenario. International Review of Research in Open and Distributed Learning, 18(6), 104-126. https://doi.org/10.19173/irrodl.v18i6.2805

Bartlett, R., Milne, R., \& Croucher, R. (2019). Strategies to improve recruitment of people with dementia to research studies. Dementia, 18(7-8), 2494-2504. https://doi.org/10.1177/1471301217748503

Bird, M., McGillion, M., Chambers, E. M., Dix, J., Fajardo, C. J., Gilmour, M., Levesque, K., Lim, A., Mierdel, S., Ouellette, C., Polanski, A.N., Reaume, S.V., Whitmore, C., \& Carter, N. (2021). A generative co-design framework for healthcare innovation: development and application of an end-user engagement framework. Research involvement and engagement, 7(1), 1-12. https://doi.org/10.1186/s40900-021-00252-7

Blomkamp, E. (2018). The promise of co-design for public policy. Australian Journal of Public Administration, 77(4), 729-743. https://doi.org/10.1111/14678500.12310Bradwell, P., \& Marr, S. (2017). Making the most of collaboration an international survey of public service co-design. Annual Review of Policy Design, 5(1), 1-27. https://www.demos.co.uk/files/CollabWeb.pdf

Branco, R. M., Quental, J., \& Ribeiro, Ó. (2017). Personalised participation: an approach to involve people with dementia and their families in a participatory design project. CoDesign, 13(2), 127-143. https://doi.org/10.1080/15710882.2017.1310903Braun, V., \& Clarke, V. (2013). Successful qualitative research: A practical guide for beginners. SAGE Publishing.

Brown, J. (2005). The world café: Shaping our futures through conversations that matter. Berrett-Koehler Publishers, Inc.

Bryden, C. (2015). Nothing about us, without us!: 20 years of dementia advocacy. Jessica Kingsley Publishers. 
Camic, P. M., Crutch, S. J., Murphy, C., Firth, N. C., Harding, E., Harrison, C. R., Howard, S., Strohmaier, S., Van Leewen, J., West, J., Windle, G., Wray, S., \& Zeilig, H. (2018). Conceptualising and Understanding Artistic Creativity in the Dementias: Interdisciplinary Approaches to Research and Practise. Frontiers in psychology, 9, 1842. https://doi.org/10.3389/fpsyg.2018.01842

Dementia Australia. (May, 2018). Dementia Australia Language Guidelines. https://www.dementia.org.au/sites/default/files/resources/dementia-languageguidelines.pdf

Faucounau, V., Riguet, M., Orvoen, G., Lacombe, A., Rialle, V., Extra, J., \& Rigaud, A. S. (2009). Electronic tracking system and wandering in Alzheimer's disease: a case study. Ann Phys Rehabil Med, 52(7-8), 579-587. https://doi.org/10.1016/j.rehab.2009.07.034

Fels, D. I., \& Astell, A. J. (2011). Storytelling as a model of conversation for people with dementia and caregivers. American Journal of Alzheimer's Disease \& Other Dementias ${ }^{\circledR}, 26(7)$, 535-541. https://doi.org/10.1177/1533317511429324

Fouché, C., \& Light, G. (2011). An Invitation to Dialogue: 'The World Cafe' In Social Work Research. Qualitative Social Work, 10(1), 28-48. https://doi.org/10.1177/1473325010376016

Fritsch, T., Kwak, J., Grant, S., Lang, J., Montgomery, R. R., \& Basting, A. D. (2009). Impact of TimeSlips, a creative expression intervention program, on nursing home residents with dementia and their caregivers. The Gerontologist, 49(1), 117-127. https://doi.org/10.1093/geront/gnp008

Goeman, D. P., Corlis, M., Swaffer, K., Jenner, V., Thompson, J. F., Renehan, E., \& Koch, S. (2019). Partnering with people with dementia and their care partners, aged care service experts, policymakers and academics: A co-design process. Australasian journal on ageing, 38, 53-58. https://doi.org/10.1111/ajag.12635

Grant, A. R., Koczwara, B., Morris, J. N., Eakin, E., Short, C. E., \& Beatty, L. (2021). What do cancer survivors and their health care providers want from a healthy living program? Results from the first round of a co-design project. Supportive Care in Cancer, 29(8), 1-12. https://doi.org/10.1007/s00520-021-06019-w

Hendriks, N., Slegers, K., \& Duysburgh, P. (2015). Codesign with people living with cognitive or sensory impairments: a case for method stories and uniqueness. CoDesign, 11(1), 70-82. 
https://doi.org/10.1080/15710882.2015.1020316INVOLVE. (2012). Briefing notes for researchers: involving the public in NHS, public health and social care research. INVOLVE. https://www.invo.org.uk/wpcontent/uploads/2012/04/INVOLVEBriefingNotesApr2012.pdf

Jessen, S., Mirkovic, J., \& Ruland, C. M. (2018). Creating gameful design in mhealth: a participatory co-design approach. JMIR mHealth and uHealth, 6(12), e11579. https://doi.org/10.2196/11579

Jootun, D., \& McGhee, G. (2011). Effective communication with people who have dementia. Nursing standard (Royal College of Nursing (Great Britain):1987), 25(25), 40-47. https://doi.org/10.7748/ns2011.02.25.25.40.c8347

Leorin, C., Stella, E., Nugent, C., Cleland, I., \& Paggetti, C. (2019). The value of including people with dementia in the co-design of personalized eHealth technologies. Dementia and geriatric cognitive disorders, 47(3), 164-175. https://doi.org/10.1159/000497804

MacFarlane, A., Galvin, R., O’Sullivan, M., McInerney, C., Meagher, E., Burke, D., \& LeMaster, J. W. (2017). Participatory methods for research prioritization in primary care: an analysis of the World Café approach in Ireland and the USA. Family Practice, 34(3), 278-284. https://doi.org/10.1093/fampra/cmw104

Miah, J., Dawes, P., Edwards, S., Leroi, I., Starling, B., \& Parsons, S. (2019). Patient and public involvement in dementia research in the European Union: a scoping review. BMC geriatrics, 19(220), 1-20. https://doi.org/10.1186/s12877-0191217-9Miles, M. B., Huberman, A. M., \& Saldaña, J. (2019). Qualitative data analysis: A methods sourcebook. SAGE publishing.

Miller, W. R., C'de Baca, J., Matthews, D. B., \& Wilbourne, P. L. (2001). Personal values card sort. University of New Mexico.

https://pdf4pro.com/view/personal-values-card-sort-the-university-of-newmexico-4bea1c.html

Niedderer, K., Harrison, D., Gosling, J., Craven, M., Blackler, A., Losada, R., \& Cid, T. (2020). Working with Experts with Experience: Charting Co-production and Codesign in the Development of HCI-Based Design. In R. Brankaert, \& G. Kenning (Eds.), HCI and Design in the Context of Dementia (303-320). Springer International Publishing. https://doi.org/10.1007/978-3-030-32835-1_19 NVivo qualitative data analysis software. (2015). QSR International Pty Ltd. Version 11. 
O’Sullivan, G., Hocking, C., \& Spence, D. (2013). Action research: Changing history for people living with dementia in New Zealand. Action Research, 12(1), 19-35. https://doi.org/10.1177/1476750313509417

Phillips, L. J., Reid-Arndt, S. A., \& Pak, Y. (2010). Effects of a creative expression intervention on emotions, communication, and quality of life in persons with dementia. Nursing research, 59(6), 417. https://doi.org/10.1097/NNR.0b013e3181faff52.

Polacsek, M., Goh, A., Malta, S., Hallam, B., Gahan, L., Cooper, C., Low, L., Livingston, G., Panayiotou, A., Loi, S., Omoro, M., Savvas, S., Batchelor, F., Ames, D., Doyle, C., Scherer, S., \& Dow, B. (2019). 'I know they are not trained in dementia': Addressing the need for specialist dementia training for home care workers. Health \& Social Care in the Community, 28, 475-484. https://doi.org/10.1111/hsc. 12880

Rapaport, P., Webster, L., Horsley, R., Kyle, S. D., Kinnunen, K. M., Hallam, B., Pickett, J., Cooper, C., Espie, C. A., \& Livingston, G. (2018). An intervention to improve sleep for people living with dementia: Reflections on the development and co-production of DREAMS: START (Dementia RElAted Manual for Sleep: STrAtegies for RelaTives). Dementia, 17(8), 976-989. https://doi.org/10.1177/1471301218789559

Repper, J., \& Carter, T. (2011). A review of the literature on peer support in mental health services. Journal of mental health, 20(4), 392-411.https://doi.org/ $\underline{10.3109 / 09638237.2011 .583947}$

Robinson, L., Brittain, K., Lindsay, S., Jackson, D., \& Olivier, P. (2009). Keeping In Touch Everyday (KITE) project: developing assistive technologies with people with dementia and their carers to promote independence. International Psychogeriatrics, 21(3), 494-502. https://doi.org/10.1017/S1041610209008448

Sanders, E. BN., \& Stappers, P. J. (2008). Co-creation and the new landscapes of design. Co-design, 4(1), 5-18. https://doi.org/10.1080/15710880701875068

Smith, L., \& Phillipson, L. (2020). Thinking through participatory action research with people with late-stage dementia: research note on mistakes, creative methods and partnerships. International Journal of Social Research Methodology, 1-6. https://doi.org/10.1080/13645579.2020.1810997 
Steen, M., Manschot, M., \& De Koning, N. (2011). Benefits of co-design in service design projects. International Journal of Design, 5(2), 53-60. http://www.ijdesign.org/index.php/IJDesign/article/view/890/346

Swanson, A. N. (2014). A day to remember: The World Dementia Café. British Journal of Wellbeing, 2(1), 11-13.

Swarbrick, C. M., Doors, O., Scottish Dementia Working Group, EDUCATE, Davis, K., \& Keady, J. (2019). Visioning change: Co-producing a model of involvement and engagement in research (Innovative Practice). Dementia, 18(78), 3165-3172.

Treadaway, C., Taylor A., \& Fennell, J. (2019). Compassionate design for dementia care, International Journal of Design Creativity and Innovation, 7(3), 144-157. https://doi.org/10.1080/21650349.2018.1501280

Trischler, J., Dietrich, T., \& Rundle-Thiele, S. (2019). Co-design: from expert-to userdriven ideas in public service design. Public Management Review, 21(11), 15951619.

Trischler, J., Kristensson, P., \& Scott, D. (2018). Team diversity and its management in a co-design team. Journal of Service Management, 29(1), 120-145. https://doi.org/10.1108/JOSM-10-2016-0283

Trischler, J., Pervan, S. J., Kelly, S. J., \& Scott, D. R. (2018). The value of Codesign: The effect of customer involvement in service design teams. Journal of Service Research, 21(1), 75-100. https://doi.org/10.1177/1094670517714060

Tsekleves, E., Bingley, AF., Luján, Escalante, MA., \& Gradinar, A. (2020). Engaging people with dementia in designing playful and creative practices: Co-design or co-creation? Dementia, 19(3):915-31. https://doi.org/10.1177/1471301218791692Vigliotti, A. A., Chinchilli, V. M., \& George, D. R. (2018). Enhancing Quality of Life and Caregiver Interactions for Persons with Dementia Using TimeSlips Group Storytelling: A 6-Month Longitudinal Study. The American Journal of Geriatric Psychiatry, 26(4), 507508. https://doi.org/10.1016/j.jagp.2017.10.001

Wang, G., Marradi, C., Albayrak, A., \& van der Cammen, T. J. (2019). Co-designing with people with dementia: A scoping review of involving people with dementia in design research. Maturitas, 127, 55-63. https://doi.org/ $\underline{10.1016 / \text { j.maturitas.2019.06.003 }}$ 


\section{Figure captions list:}

Figure 1: Average scores on evaluation of PITCH co-design workshops 1 and 2 from 37 participants

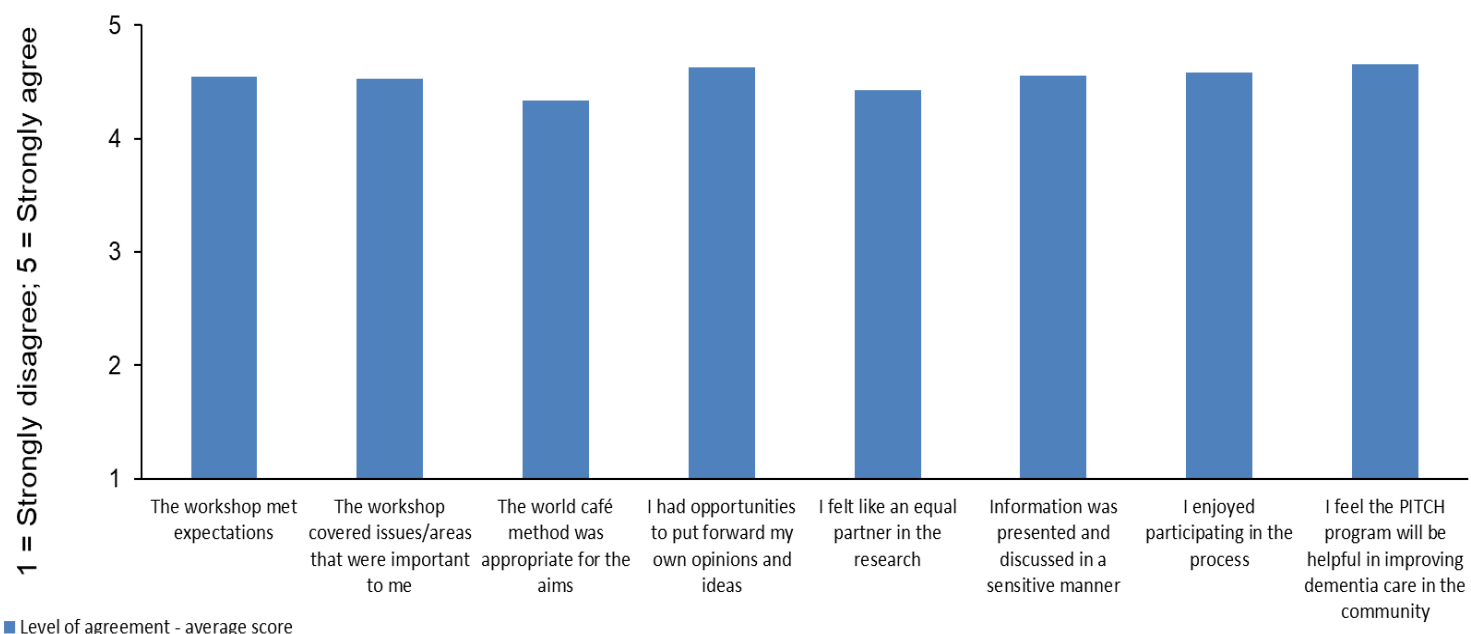

Figure 2: Average scores on the evaluation of PITCH co-design workshops 3 and 4 from 27 participants, including opinions from participants on the PITCH prototype they started co-designing in workshops 1 and 2 that they were refining.

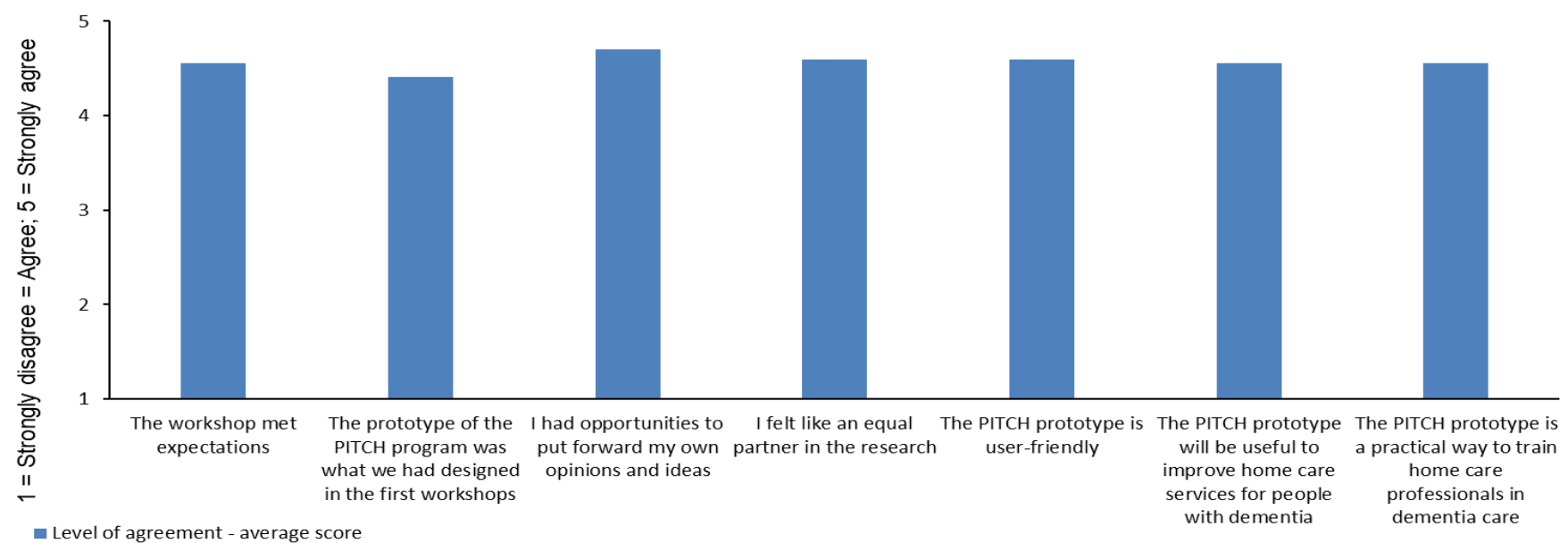


Figure 3. Average scores on the evaluation of PITCH pilot by 11 experienced dementia specialist home care workers

\section{Overall evaluation of PITCH workshops}

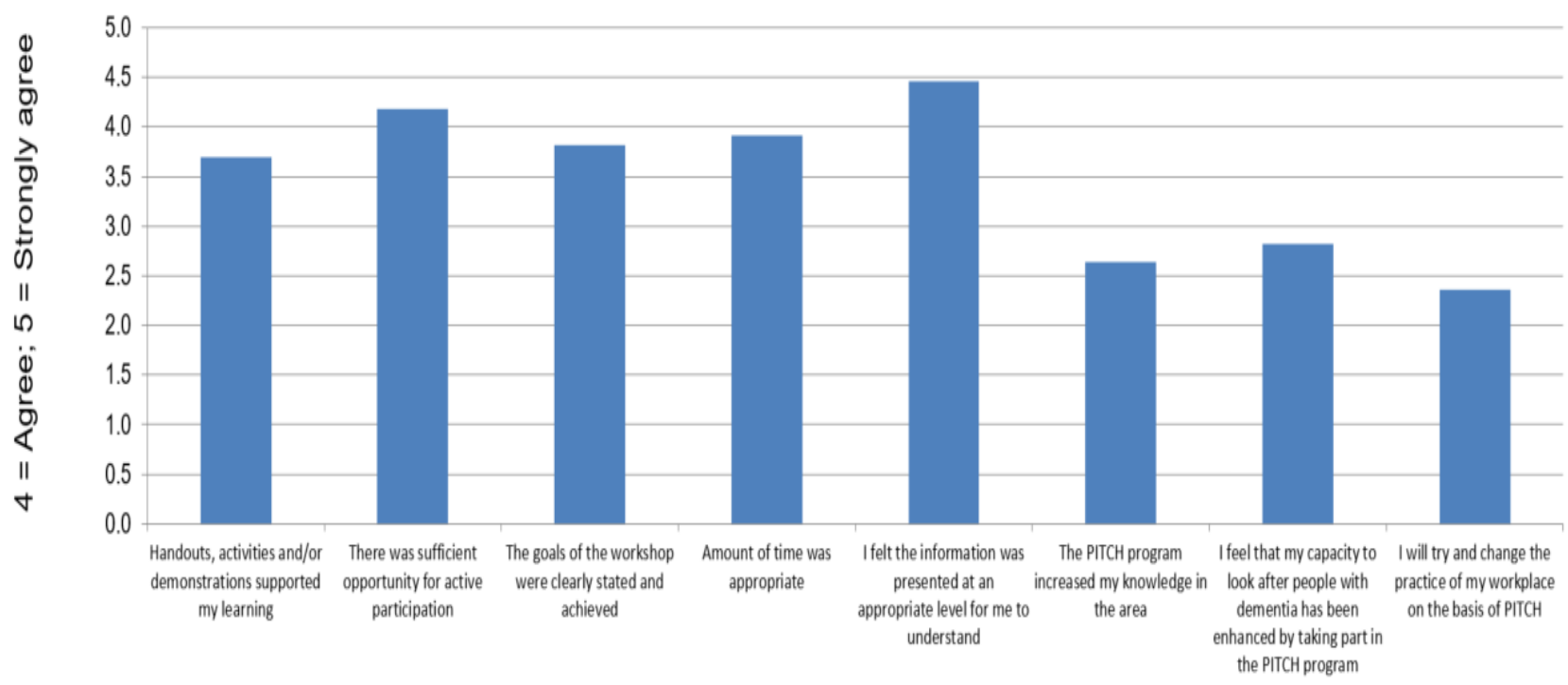

